\title{
Understanding the relationship views and sex motives of call center workers and its implications to sexual practices
}

Batara, Jame Bryan L. $\bowtie$

Department of Psychology, University of San Carlos, Philippines (jamebatara5@gmail.com)

Areopagita, Gladys Gil V.

University of San Carlos, Philippines

Cherubs Academy, Inc., Philippines (agladysgil@gmail.com)

Yu, Erwin D.

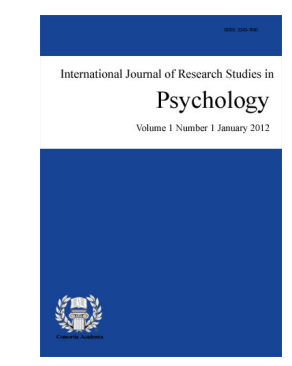

ISSN: $2243-7681$ Online ISSN: 2243-769X

OPEN ACCESS

University of San Carlos, Philippines (erwin_d_yu@yahoo.com)

Received: 13 September $2015 \quad$ Revised: 1 November $2015 \quad$ Accepted: 5 November 2015

\section{Abstract}

The current study aimed to explore the levels of attachment dimensions and common sex motives of call center workers (CCW) specifically in Cebu City, Philippines. It was the thrust of the study to provide a plausible account in understanding the sexual practices of CCWs amid the data suggesting risky practices among them. Both online and pen-and-paper surveys were employed. Descriptive results showed that call center workers in Cebu City are relatively high in attachment anxiety and low in attachment avoidance. Common sex motives of call center workers include intimacy and enhancement motives. Regression analysis showed that both attachment anxiety and attachment avoidance predicted partner approval, peer pressure, self-affirmation, coping, and intimacy motives. Implications of the findings of this exploratory study contribute to further our understanding about the sexual practices of CCWs in the Philippines.

Keywords: attachment anxiety; attachment avoidance; sex motives; risky sexual practices; call center workers 


\section{Understanding the relationship views and sex motives of call center workers and its implications to sexual practices}

\section{Introduction}

A call center boom hit the Philippines in 2001, generating thousands of job opportunities to young Filipino men and women. These young professionals enjoy relatively high compensation plus attractive benefits. But all these benefits coupled with the demands of the job, like unusual work hours, heavy workload and stress, may result in risky lifestyles (Gayares \& Romero, 2010). DOH statistics showed 96 recorded HIV cases in Cebu City from 1989 to January 2010 and of that number, most were call center workers. Doctor Eric Tayag, chief of the National Epidemiology Center of the Department of Health, added that call center workers have high-risk sexual behaviors that should be looked into (Baguio, 2010). However, it has to be taken into account that working in a BPO industry does not necessarily entail that such industry facilitates risky sexual behaviors. Other factors may contribute to these risky sexual practices. There have been growing studies to understand CCWs in terms of their sexual behaviors which suggest that both social and psychological factors may contribute to their risky sexual practices (e.g., Melgar, Bangi, Mandel, \& McFarland, 2011; Melgar, Ofreneo, \& Kintanar, 2009). To provide further understanding on the sexual practices of CCWs, the present study sought to explore their attachment dimensions and sex motives and look into the implications of these variables in the CCWs' sexual practices.

CCWs engaged in sexual behaviors that were considered risky because of its high chance of contracting sexually transmitted infections. These risky sexual behaviors include paying for sex, multiple sexual partners, extra-relational sex, and having sex under the influence of alcohol and/or drugs (Melgar et al., 2009). Another study in 2010 conducted by the University of the Philippines Population Institute in collaboration with the Department of Health found that more call center workers have a regular non-romantic sexual relationship and casual sex, with more males engaging in such behavior. In the same study, a few of the CCWs paid for sex. A voluntary HIV testing done by the Philippine General Hospital in 2009 has found among those who were positive, half of them were CCWs (mentioned in Melgar et al., 2011). Lastly, the focus group discussions on understanding the risky sexual practices of CCWs suggest that stressful and shifting schedule (usually night shifts), close and confined social interactions with fellow CCWs in the workplace, and the non-traditional means of relieving stress (e.g., casual sex, cigarette smoking, alcohol use) serve to facilitate risky sexual practices (Melgar et al., 2011).

Though the results in the aforementioned studies indicated that call center workers engage in risky sexual practices and several factors serve to facilitate these practices, other social/psychological variables may also warrant interesting implications. Melgar and colleagues (2009) acknowledged that a number of factors may influence the decision to use condoms during sexual intercourse and these factors include age, gender and the cultural norms of the call center workers. That being said, the risky trends among young people include early sexual debut, multiple sexual relationships, and risky sexual behaviors (Farr \& Wilson, 2010; Palabrica-Costello, 2004; Raymundo, 2004). Psychological factors, such as nature of sexual relationship, views on the relationship, and the reasons for engaging in sex may also play roles. This study specifically looks into the levels of attachment dimensions and sex motives among CCWs, and its implication to risky sexual practices.

Attachment is a "stable tendency of an individual to make substantial efforts to seek and maintain proximity to and conduct with one or few specific individuals who provide the subjective potential for physical and/or psychological safety and security" (Berman \& Sperling, 1994, p. 8). Adult romantic attachment is measured through two dimensions - anxiety and avoidance. Attachment anxiety reflects the degree to which an individual worries that his/her partner will not be available in times of need whereas attachment avoidance reflects the degree to which an individual distrusts the relationship partner and attempts to maintain independence and emotional distance from partners (Mikulincer \& Shaver, 2007). 
The relationship views and sex motives of call center workers and its implications to sexual practices

Levels of attachment dimensions have vast implications in an individual's risky sexual practices. For example, highly anxious individuals seldom use condoms during sexual intercourse, and seldom discuss risky sexual behaviors with their partners, with the fear of pushing away partners by talking about AIDS-related issues (Cooper, Shapiro, \& Powers, 1998; Feeney, Peterson, Gallois, \& Terry, 2000). Anxious individuals engage early in sex or have multiple sex partners, and commit infidelity (Bogaert \& Sadava, 2002). Because an anxious individual fears rejection, engaging in sex may calm their concerns of rejection and abandonment, and foster intense closeness with the partner (Tracy, Shaver, Albino, \& Cooper, 2003). In contrast, individuals high in attachment avoidance are likely to be hurtful to their partners, avoid talking about their and their partner's sexual histories (Schachner \& Shaver, 2004), and use alcohol and drugs to reduce tension associated with sexual encounters (Tracy et al., 2003). They are also more likely to inject drugs before any sexual encounters (Feeney et al., 2000). These risky behaviors reflect the avoidant individual's emotional distance and discomfort in relationships. With this, knowing the levels of attachments dimension among CCWs offers a way in understanding their involvement in risky sexual practices.

In terms of the motives for sex, anxiously attached individuals use sex to calm their concerns of rejection and abandonment, and to foster intense closeness (Tracy et al., 2003). Moreover, they engage in sexual interactions to feel valued, to make their partners love them more, and to help themselves feel better (Schachner \& Shaver, 2004). Finally, anxious individuals engage in sex to please their partner, to avoid relationship conflict, and to promote intimacy (Impett, Gordon, \& Strachman, 2008). For avoidant individuals, reasons for sexual encounters do not involve the promotion of intimacy or the expression of warm feelings for their partners; instead sex is done for nonromantic reasons (Cooper et al., 2006; Davis, Shaver, \& Vernon, 2004), such as to avoid negative social experiences and threats to self-esteem, to satisfy their own pleasure, to be able to brag about it, and to enhance their view of themselves (Schachner \& Shaver, 2004).

The findings on attachment dimensions and sex motives were theoretically linked. Individuals high in attachment anxiety are characterized by fear of rejection and abandonment, therefore, they likely engage in sex to please their partner and to make their partner love them more, so as to avoid relationship conflict that would likely lead to separation. Individuals high in attachment avoidance are characterized by discomfort with closeness, thus, they likely engage in sex to avoid threats to self-esteem, to be able to brag about it, and to satisfy their own pleasure with mostly no intention of promoting intimacy in the relationship. These associations can offer a plausible explanation in understanding the risky sexual practices of CCWs. With this, the current study investigated the associations of attachment dimensions and sex motives, and look into the implications of its associations toward the risky sexual practices of CCWs in the Philippines in which the majority were those in Cebu City.

\subsection{Research Problem}

The present study aims to the answer the following research questions:

1. What are the levels of attachment anxiety and attachment avoidance of CCWs?

2. What are the common reasons of CCWs for engaging in sex?

3. Is there a relationship between attachment anxiety and sex motives of CCWs?

4. Is there a relationship between attachment avoidance and sex motives of CCWs?

5. Do attachment anxiety and attachment avoidance predict sex motives of CCWs? 


\section{Methods}

\subsection{Design}

With a quantitative research design, the current study used self-administered questionnaires (survey forms). The survey forms contain two self-report questionnaires. To measure attachment dimensions, ECR-R (Experiences in Close Relationships-Revised; Fraley, Waller, \& Brennan, 2000) was used. To measure sex motives, SMS (Sex Motives Scale; Cooper, Shapiro, \& Powers, 1998) was used.

Because of the perception of call center companies that they have been stigmatized as an industry that fosters risky sexual practices (Baguio, 2010; Cayabyab, 2013), we found difficulty in formally asking permission to conduct the survey in their workplace. With this, convenience and snowball sampling were utilized for gathering survey respondents. Confidentiality was ensured among respondents especially because of the sensitivity of the information they were giving.

\subsection{Participants}

The age of the CCW respondents $(N=150)$ ranges from 18-39 years with a mean age of 25 years $(S D=4.1$ $y r s)$. Call center work experience ranges from 5 months to 6 years and 5 months $(S D=17.6$ months $)$. Of the total sample, male respondents comprise 51 percent whereas female 49 percent and all were sexually experienced. As for the gender preference, 83 percent were heterosexual, 11 percent homosexual, and 5 percent bisexual. Among males, 78 percent of call center workers prefer opposite sex partners whereas 16 percent prefer same sex and 6 percent for both sexes. Among females, 89 percent of call center workers prefer opposite sex partners whereas 7 percent for same sex and only 4 percent for both sexes. In addition, 37 percent were single, 10 percent married, and in general, 52 percent were currently in a relationship. In gathering the respondents for this study, the current researchers used online survey (33 respondents) and pen-and-paper survey forms (117 respondents). The online survey contained the same set of questions with the survey forms except for some safeguard mechanisms which ensured the data entered were valid.

\subsection{Instruments}

Attachment Dimensions: ECR-R. Experiences in Close Relationships-Revised (Fraley, Waller, \& Brennan, 2000). This scale was used to measure the levels of attachment anxiety and avoidance of the CCW respondents. ECR-R is a 36-item self-report questionnaire containing 18 items measuring avoidance and 18 items measuring anxiety. Examples of avoidance items include "I find it difficult to allow myself to depend on romantic partners" and "I get uncomfortable when a romantic partner wants to be very close." Examples of anxiety items include "I often worry that my partner doesn't really love me" and "I rarely worry about my partner leaving me" (reverse scored). In our sample, the reliability coefficients were strong for both anxiety $(\alpha=0.90)$ and avoidance $(\alpha=$ $0.88)$.

Sex Motives: Sex Motives Scale (Cooper et al., 1998). This scale was used to measure the motives for sex among CCW respondents. The 29-item Sex Motives Scale is based on a functionalist perspective, in which there are few key motivational dimensions underlying human behavior (e.g., approach vs. avoidance, autonomy vs. relatedness). This test contains 6 subscales that measure different types of motives coming from the four motivational dimensions (Social Approach Motive, Intrapersonal Approach Motive, Intrapersonal Aversive Motive and Social Aversive Motive). The 6 subscales are Intimacy Motive (5 items such as "How often do you have sex to feel emotionally close to your partner?"), Enhancement Motive (5 items such as, "How often do you have sex because it feels good?"), Self-Affirmation Motive (5 items such as, "How often do you have sex to reassure yourself that you are sexually desirable?"), Coping Motive (5 items, such as, "How often do you have sex to cheer yourself up?"), Peer Pressure Motive (5 items, such as, "How often do you have sex because others will kid you if you don't?"), and Partner Approval Motive (4 items, "How often do you have sex because you 
The relationship views and sex motives of call center workers and its implications to sexual practices

don't want your partner to be angry with you?"). Cooper, Shapiro and Powers (1998) found high reliability coefficients using Sex Motives Scale (Intimacy $=.90$, Enhancement $=.87$, Self-Affirmation $=.87$, Peer Pressure $=.87$, Partner Approval $=.84$, Coping =.82). The reliability coefficients for these scales in the current study's sample were strong ranging from .84 to .90 .

\subsection{Procedure}

Call center workers usually spend their break time at coffee shops, restaurants and fast food outlets within the vicinity of the Asia Town I.T. Park. We conducted the survey in these places where they usually hang out. The researchers politely approached the potential participants and asked if they were willing to be part of the study. The participants were given an overview regarding the study. If they chose to participate in the study, they were given the survey forms that were sealed in an envelope. They were also instructed to honestly answer the survey forms individually without any consultation from their friends. Each participant had 15 to 30 minutes to complete the survey form. Once they had completed the survey forms, they resealed it back into the envelope and submitted it to the person administering the survey. Afterwards, the researcher debriefed the participants and incentives were given.

Moreover, snowball sampling was also conducted. Call center workers interested in the study were given survey forms and incentives and were instructed to let their friends who were also call center workers answer the survey. Aside from the data gathering stated above, an online survey was also conducted. The online survey contained the same set of questions with the survey forms except for some safeguard mechanism that ensured the data entered were valid. For those who answered, they were required to give their email address, and these email addresses were checked whether these were valid or not. If these were not valid, the data were discarded. Another security mechanism was to ask the participants to enter their name initials with their birthday (e.g., Juan Dela Cruz, JDC090682). This enabled us to check the validity of the data.

\section{Results}

The present study aimed to explore the levels of attachment anxiety and avoidance of CCWs, their common reasons for engaging in sex, and whether their levels of attachment predict these reasons for engaging in sex. CCWs showed slightly higher attachment anxiety $(M=3.93, S D=1.09)$ compared to attachment avoidance $(M$ $=2.95, S D=0.90)$. They usually engage in sex for intimacy $(M=4.69, S D=1.26)$ and enhancement $(M=4.45$, $S D=1.45)$ motives. They sometimes engage in sex for reasons of self-affirmation $(M=3.31, S D=1.40)$ and coping $(M=3.19, S D=1.49)$. They seem unlikely to engage in sex for partner approval $(M=2.7, S D=1.4)$ and peer pressure $(M=2.3, S D=1.4)$ motives.

In terms of the associations between attachment dimensions and sex motives among CCWs, significant correlations were found. Attachment anxiety was positively correlated with partner approval $[r(150)=.402$, $p<.001]$, peer pressure motive $[r(150)=.324, p<.001]$, self-affirmation $[r(150)=.232, p<.01]$, and coping $[r(150)=.198, p<.05]$ motives. On the other hand, attachment anxiety was not correlated with intimacy motive $[r(150)=-.003, p>.05]$. Attachment avoidance was positively correlated with peer pressure $[r(150)=.447$, $p<.01]$, self-affirmation $[r(150)=.231, p<.01]$, coping $[r(150)=.232, p<.01]$, and partner approval $[r(150)=.458, p<.001]$ motives. Negative correlation was found between attachment avoidance and intimacy motive $[r(150)=-.227, p<.01]$. Attachment avoidance was not correlated with enhancement motive $[r(150)=$ $-.118, p>.10]$.

To determine whether attachment dimensions of CCWs predict their reasons for engaging in sex, a multiple regression analysis was conducted (see table 1). Results suggested that both attachment anxiety and attachment avoidance significantly predicted partner approval $[F(2,147)=29.801, p<.001]$, peer pressure $[F(2,147)=$ $23.270, p<.01]$, self-affirmation $[F(2,147)=6.634, p<.01]$, coping $[F(2,147)=5.720, p<.01]$, and intimacy motives $[F(2,147)=4.353, p<.05]$, but not enhancement motive $[F(2,147)=1.154, p>.05]$. Both attachment 
Batara, J. B. L., Areopagita, G. G., \& Yu, E. D.

anxiety and avoidance could explain relatively high percentage of the variance of partner approval $\left(R^{2}=.279\right)$ and peer pressure $\left(R^{2}=.230\right)$ motives. Both correlation and regression results showed no significance with regards to enhancement motive.

\section{Table 1}

Multiple Regression Analysis with Anxiety \& Avoidance Dimensions as Predictors of Sex Motives $(N=150)$

\begin{tabular}{|c|c|c|c|c|c|c|}
\hline & \multicolumn{2}{|c|}{ Constant } & \multicolumn{2}{|c|}{$\beta$} & \multirow{2}{*}{$\mathrm{F}(2,147)$} & \multirow{2}{*}{ Adj. $\mathrm{R}^{2}$} \\
\hline & $\mathrm{B}$ & SE B & $\mathrm{Ax}$ & $\mathrm{Av}$ & & \\
\hline Partner Approval & -.464 & .427 & $.293^{* *}$ & $.372 * *$ & $29.801 * * *$ & .279 \\
\hline Peer Pressure & -.487 & .437 & $.210^{* *}$ & $.385 * *$ & $23.270 * * *$ & .230 \\
\hline Self-affirmation & 1.587 & .487 & $.180 *$ & $.178 *$ & $6.634 * *$ & .070 \\
\hline Coping & 1.5 & .520 & $.142 \dagger$ & $.190 *$ & $5.720 * *$ & .060 \\
\hline Intimacy & 5.387 & .444 & $.070 \dagger \dagger$ & $-.247 * *$ & $4.353 *$ & .043 \\
\hline
\end{tabular}

\section{General Discussion}

The present study aimed to explore the levels of attachment anxiety and avoidance of CCWs, their common reasons for engaging in sex, and whether their levels of attachment predict these reasons for engaging in sex. Among the CCW respondents, attachment anxiety was relatively higher than attachment avoidance. Moreover, CCWs high in attachment anxiety would likely engage in sex to induce their partner to love them more, to avoid negative social experiences and threats to self-esteem, to cope with stressful or negative situations, and to feel confident and desirable. CCWs high in attachment avoidance would likely engage in sex to avoid negative social experiences and threats to self-esteem, for partner approval, to cope with negative situations, to feel confident and desirable, and they would not likely engage in sex for intimacy.

Call center workers were relatively high in attachment anxiety, and relatively low in attachment avoidance. This has several implications on their sexual practices. Based on previous studies, relatively high attachment anxiety may contribute to risky sexual practices. Highly anxious individuals seldom use condoms during sexual intercourse, and seldom discuss risky sexual behaviors with their partners, with the fear of pushing away partners by talking about AIDS-related issues (Cooper et al., 1998; Feeney et al., 2000). Anxious individuals engage early in sex or have multiple sex partners, and commit infidelity (Bogaert \& Sadava, 2002). All these point to the greater risk of contracting and acquiring sexually transmitted diseases.

Results of the present study suggest that call center workers high in attachment anxiety use sex to gain greater proximity to partner, and to decrease feelings of anxiety and distress. These motives may likely lead to rejection, hurt feelings and physical or psychological abuse (Davis, Ace, \& Andra, 2002). In addition, the higher the anxiety, the greater the tendency to experience negative feelings (such as shame), as well as indifference, detachment, and distraction by relational concerns (Birnbaum, 2007).

Sex motives also play a role in the interpersonal well-being of the call center workers. It was found that motives for sex were powerful predictors of well-being (Impett, Peplau, \& Gable, 2005). When individuals engage in sex for approach motives (obtaining positive outcomes such as physical pleasure, partner's happiness, or enhanced intimacy in relationship), they experienced more positive emotions, greater relationship well-being in terms of satisfaction and closeness, and less relationship conflict. In this connection, intimacy and enhancement motives, both of which are approach motives, were the top sex motives of call center workers. This may indicate that, in the context of romantic relationships, call center workers experience positive emotions, 
greater relationship well-being, and less relationship conflict. In contrast, when individuals engage in sex for avoidance motives (avoiding negative outcome such as sexual frustration, partner's loss of interest in the relationship, conflict in relationship), they experienced more negative emotions, more relationship conflict, and less positive relationship well-being (Impett et al., 2005).

In general, the current findings offer practical implications regarding the sexual practices of call center workers. However, the generalizability of these findings as well as other limitations should be taken into consideration. Difficulty in finding respondents willing to participate (due to the sensitivity of the subject matter) in the survey led to convenience sampling. Moreover, the impression of others that call centers are a hub for risky sexual practices (Baguio, 2010; Cayabyab, 2013) made these companies hesitant and not willing to participate in the study. The sample gathered consisted mostly of call center workers only in Cebu City, who were mostly single in terms of civil status but are sexually active and in a romantic relationship at the time of the survey. It should also be in mind that the survey did not ask whether they engage in risky sexual practices or not. Thus, the participants are not representative of the CCWs who engage in risky sexual practices but are composed of Cebuano CCWs in general. Moreover, samples of married call center workers and call center workers outside Cebu City may be included in the future research to extend the generalizability of the current findings.

Despite these limitations, the findings on levels of attachment dimensions and common sex motives among CCWs offered valuable insights. Notably, both the attachment anxiety and attachment avoidance predicted a large percentage of partner approval and peer pressure motives. Thus, a CCW who exhibits fear of abandonment by a partner and discomfort in relationships would likely engage in sex for reasons of partner approval and peer pressure. Having sex to appease one's partner (partner approval) was related to greater risk taking, less effective birth control use, and more unplanned pregnancies (Cooper et al., 1998). Excessive concern about partner approval has been also shown to undermine safe sex behaviors (Harlow, Quina, Morokoff, Rose, \& Grimley, 1993). Furthermore, Cooper and colleagues (1998) also found that individuals high in peer pressure motives showed increase in risky sexual practices and less improvement in contraceptive practices across time. Attachment anxiety and avoidance were predictive of partner approval and peer pressure motives - motives associated with risky sexual practices. Hence, knowing the attachment dimensions of call center workers and their motives for sex may be helpful in terms of understanding their sexual practices. This, in turn, provides implications on the sexual practices of CCWs.

Philippines is now considered as the largest provider of call center workers in the BPO industry (Periabras, 2013). Thus, a need to further understand the workers in this growing industry has an impact on the longevity of the industry as well as to the health of the CCWs. One way of understanding the CCWs in terms of their sexual practices is through their relationship views and motives for sex. Ojo and colleagues (2011) found that voluntary counseling and testing in the workplace facilitates the increase for those who wanted to be tested for HIV. With the present study's results in mind, the program for voluntary counseling and testing in the organizational/work setting may include the CCWs' view of their relationships and some reasons of their engaging in sex. Aside from the direct question of whether they engage in risky sex or not, nonthreatening series of questions regarding their motivations for sex and their view of relationships may provide us some relevant information on their tendency to engage in risky sex. However, the direct questions regarding their risky sex behaviors are still crucial. What the present study tries to convey is the idea that in group gatherings, threatening questions related to risky sex behaviors may not warrant truthful answers. Thus, non-threatening questions may warrant truthful answers and somehow can provide us some clues on whether a CCW engages in risky sex or not. From there, further testing and intervention may proceed.

Moreover, insecure attachment (high attachment anxiety or high attachment avoidance) also have negative influence in the learning readiness and attention of individuals (Larose, Bernier, \& Tarabulsy, 2005). With this, knowing the levels of attachment dimensions of the CCWs may help those helping professionals (i.e., teachers, researchers, management personnel) devise intervention programs which may be fit towards not only those CCWs who are prepared to learn safe sex practices but also those who may be hesitant and not willing to learn. 
Lastly, the findings of the current study contribute to the understanding of the view of relationships and sex motives of Filipino call center workers. This, in turn, may serve as one of the ways in understanding their sexual practices.

\section{Conclusion}

The present study's aim was to provide an alternative explanation in understanding the sexual practices of CCWs in the Philippines. In this case, the implications of attachment dimensions and sex motives were sought as explanatory factors. Attachment anxiety and attachment avoidance among call center workers are associated with engaging in sex to please their partner, to affirm themselves, to cope with negative emotions and to avoid negative social experiences. On the other hand, call center workers high in attachment avoidance would not likely engage in sex for reasons of fostering intimacy in the relationship. These showed practical implications in understanding the sexual practices of CCWs. Despite the study's limitations, the current study has given empirical evidence that disputes the common thinking that the risky sexual practices of call center workers are attributed to the fact that they are working in the call center industry. Hence, it is more appropriate to say that a lot of factors contribute to these risky sexual practices, and attachment dimensions and sex motives have been shown to be some of these factors.

\section{References}

Baguio, M. A. (2010, January 30). According to study: Call center agents prone to HIV-AIDS. The Philippine Star. Retrieved from http://www.philstar.com/cebu-news/544838/according-study-call-center-agents-prone-hiv-aids

Berman, W. H., \& Sperling, M. B. (1994). The structure and function of adult attachment. In W.H. Berman \& M. B. Sperling (Eds.), Attachment in Adults: Clinical perspectives (pp. 1-30). New York: Guilford Press.

Birnbaum, G. (2007). Attachment orientations, sexual functioning, and relationship satisfaction in a community sample of women. Journal of Social and Personal Relationships, 24, 21-35. http://dx.doi.org/10.1177/0265407507072576

Bogaert, A. F., \& Sadava, S. (2002). Adult attachment and sexual behavior. Personal Relationships, 9, 191-204.

Cayabyab, M. J. (2013, May 28). No more SEX in health campaign for call center agents. GMA News. Retrieved from http://www.gmanetwork.com/news/story/310390/news/nation/no-more-sex-in-health-campaign-for-callcenter-agents

Cooper, M. L., Pioli, M., Levitt, A., Talley, A. E., Micheas, L., \& Collins, N. L. (2006). Attachment styles, sex motives, and sexual behavior: Evidence for gender-specific expressions of attachment dynamics. In M. Mikulincer \& G. S. Goodman (Eds.), Dynamics of romantic love: Attachment, caregiving, and sex (pp. 243-274). New York: Guilford. http://dx.doi.org/10.1111/1475-6811.00012

Cooper, M. L., Shapiro, C. M., \& Powers, A. M. (1998). Motivations for sex and risky sexual behavior among adolescents and young adults: A functional perspective. Journal of Personality and Social Psychology, 75, 1528-1558. http://dx.doi.org/10.1037/0022-3514.75.6.1528

Davis, D., Shaver, P. R., \& Vernon, M. L. (2004). Attachment style and subjective motivations for sex. Personality and Social Psychology Bulletin, 30, 1076-1090. http://dx.doi.org/10.1177/0146167204264794

Davis, K. E., Ace, A., \& Andra, M. (2002). Stalking perpetrators and psychological maltreatment of partners: Anger-jealousy, attachment insecurity, need for control, and break-up context. In K. E. Davis \& I. H. Frieze (Eds.), Stalking: Perspectives on victims and perpetrators (pp. 237-264) New York: Springer.

Farr, A. C., \& Wilson, D. P. (2010). An HIV epidemic is ready to emerge in the Philippines. Journal of the International AIDS Society, 13(1), 16. http://dx.doi.org/10.1186/1758-2652-13-16

Feeney, J. A., Peterson, C., Gallois, C., \& Terry, D. J. (2000). Attachment style as a predictor of sexual attitudes and behavior in late adolescence. Psychology and Health, 14, $1105-1122$. 
The relationship views and sex motives of call center workers and its implications to sexual practices http://dx.doi.org/10.1080/08870440008407370

Fraley, R. C., Waller, N. G., \& Brennan, K. A. (2000). An item response theory analysis of self-report measures of adult attachment. Journal of Personality and Social Psychology, 78, 350-365. http://dx.doi.org/10.1037/0022-3514.78.2.350

Gayares, C. B., \& Romero, G. (2010, January). Young professionals in Manila and Metro Cebu: How healthy are they? Retrieved from http://www.ovcrd.upd.edu.ph/oldweb/index.php?option=com_content\&task=view\&id=618

Harlow, L. L, Quina, K., Morokoff, P. J., Rose, J. S., \& Grimley, D. M. (1993). HIV risk in women: A multifaceted model. Journal of Applied Biobehavioral Research, 1, 3-38. http://dx.doi.org/10.1111/j.1751-9861.1993.tb00025.x

Impett, E. A., Gordon, A. M., \& Strachman, A. (2008). Attachment and daily sexual goals: A study of dating couples. Personal Relationships, 15, 375-390. http://dx.doi.org/10.1111/j.1475-6811.2008.00204.x

Impett, E., Peplau, L., \& Gable, S. (2005). Approach and avoidance sexual motives: Implications for personal and interpersonal well-being. Personal Relationships, 12, 465-482. http://dx.doi.org/10.1111/j.1475-6811.2005.00126.x

Larose, S., Bernier, A., \& Tarabulsy, G. M. (2005). Attachment state of mind, learning dispositions, and academic performance during the college transition. Developmental Psychology, 41(1), 281-289. http://dx.doi.org/10.1037/0012-1649.41.1.281

Melgar, I., Ofreneo, M., \& Kintanar, N. (2009). Risk Behaviors for HIV/AIDS among Call Center Employees in the Philippines. Retrieved from http://www.ilo.org/manila/whatwedo/publications/lang--en/docName--WCMS_140906/index.htm

Melgar, M., Bangi, A., Mandel, J., \& McFarland, W. (2011). A survey of risky behaviors among employees in offshore business processing centers. Philippine Population Review, 10(1), 1-22.

Mikulincer, M., \& Shaver, P. R. (2007). Attachment in adulthood: Structure, dynamics and change. New York: Guilford.

Ojo, O., Verbeek, J. H., Rasanen, K., Heikkinen, J., Isotalo, L. K., Mngoma, N., \& Ruotsalainen, E. (2011). Interventions to reduce risky sexual behaviour for preventing HIV infection in workers in occupational settings. The Cochrane Library. Retrieved from http://www.profnatali.it/uploadedfiles/o_18goj810d145m1gjtjh1ecq1tv8.pdf http://dx.doi.org/10.1002/14651858.cd005274.pub3

Palabrica-Costello, M. (2004). Global research studies on adolescent sexuality, reproductive health and fertility. Philippine Population Review, 3, 19-54.

Periabras, R. C. (2013, October 26). Philippines: The new call center capital of the world. The Manila Times. Retrieved from http://www.manilatimes.net/philippines-the-new-call-center-capital-of-the-world/47984/

Raymundo, C. (2004). Sexuality and reproductive health of Filipino adolescents. Philippine Population Review, $3(1), 55-78$.

Schachner, D. A., \& Shaver, P. R. (2004). Attachment dimensions and sexual motives. Personal Relationships, 11, 179-195. http://dx.doi.org/10.1111/j.1475-6811.2004.00077.x

Tracy, J. L., Shaver, P. R., Albino, A. W., \& Cooper, M. L. (2003). Attachment styles and adolescent sexuality. In P. Florsheim (Ed.), Adolescent romantic relations and sexual behavior: Theory, research, and practical implications (pp. 137-159). Mahwah, NJ: Erlbaum.

University of the Philippines Population Institute [UPPI]. (2010). Lifestyle, health status and behavior of young workers in call centers and other industries: Metro Manila and Metro Cebu. Quezon City, Philippines: University of the Philippines Population Institute. 
Batara, J. B. L., Areopagita, G. G., \& Yu, E. D. 